\title{
O direito humano e a proteção social no Mercosul: a política de assistência social em territórios fronteiriços
}

\author{
Human Rights and Social Protection in Mercosur: Social Assistance Policy in Border \\ Regions \\ Helenara Silveira Fagundes* \\ Vera Maria Ribeiro Nogueira** \\ Ineiva Terezinha Kreutz***
}

\begin{abstract}
Resumo
O objetivo deste artigo é compreender a institucionalidade das ações de proteção social inscritas no Plano Estratégico de Ação Social (PEAS), proposto pelo Instituto Social do Mercosul (ISM), e sua interface com a política de assistência social em territórios fronteiriços. Apresenta os resultados de uma pesquisa de caráter exploratório, sendo utilizadas para a coleta de informações a análise documental e a sistematização dos dados através da análise de conteúdo. Entre os resultados salientase a importância de se estudar as decisões, acordos, recomendações emanadas no âmbito do Mercosul para se discutir a estruturação da cidadania social. Destaca-se, no PEAS, a indicação do fortalecimento das fronteiras, da promoção de intercâmbio de iniciativas e experiências exitosas, e da necessidade de assegurar os direitos humanos. Outro ponto a se destacar é a relevância dos acordos, quando internalizados na ordem jurídica dos países e acompanhados de normativas nacionais que os materializem, pois, conforme indicação do PEAS, o desenvolvimento das regiões de fronteira pode diminuir as desigualdades sociais nos níveis nacional e internacional. Conclui-se pela estreita relação entre as proposições do PEAS e a política de assistência social em espaços fronteiriços nos marcos dos direitos humanos.
\end{abstract}

Palavras-chave: Fronteiras. Mercosul. Direitos humanos. Proteção social. Assistência social.

\section{Abstract:}

The objective of this article is to understand the institutional incorporation of social protection actions inscribed in the PEAS, with consequences on social assistance policy in border regions. This is an exploratory study and involves a data survey including document analysis and content analysis. It emphasizes the importance of studying the decisions, agreements and recommendations emanating from the realm of Mercosur to discuss the organization of social citizenship. Within the Mercosur Strategic Social Action Plan stands out the indication to strengthen borders; the promotion of exchange of successful initiatives and experiences; and the need to assure human rights. Another point highlighted is the importance of agreements, when internalized in the legal orders of the countries and accompanied by domestic norms that materialize the accords. Because as indicated by the Mercosur Strategic Social Action Plan, the development of border regions can lead to decreasing social inequalities at national and international levels. It is concluded by the close relationship between the proposals of the PEAS and the policy of social assistance in frontier spaces in the framework of the human rights.

Keywords: Borders. Mercosur. Human rights. Social protection. Social assistanc.

\footnotetext{
* Assistente Social, Professora do Departamento de Serviço Social e do Programa de Pós-Graduação em Serviço Social da Universidade Federal de Santa Catarina (UFSC), Doutora em Serviço Social. E-mail: helenarasf@hotmail.com

** Assistente Social, Professora do Programa de Pós-Graduação em Serviço Social da Universidade Federal de Santa Catarina (UFSC) e do Programa de Pós-graduação em Política Social e Direitos Humanos da Universidade Católica de Pelotas (UCPel), Doutora em Enfermagem. E-mail: veramrn@gmail.com

*** Assistente Social, Professora curso de Serviço Social da Universidade Estadual do Oeste do Paraná (UNIOESTE), campus de Toledo; Doutoranda do Programa de Pós Graduação em Serviço Social da Universidade Federal de Santa Catariana (UFSC). E-mail: ineivakreutz@gmail.com
} 


\section{Introdução}

O presente artigo tem como objetivo apreender a institucionalidade ${ }^{1}$ das ações de proteção social inscritas no Plano de Ação Social do Mercosul (PEAS) elaborado pelo Instituto Social do Mercosul (ISM) e sua interface com a política de assistência social ${ }^{2}$ em territórios fronteiriços. Esta pesquisa tem caráter exploratório. Como metodologia para a coleta de informações, foi utilizada a análise documental (PEAS), e a sistematização dos dados foi realizada através da análise de conteúdo e uso do software webQDA. Os documentos, como produtos de uma sociedade, são fontes históricas e significativas de análise das relações sociais em contextos determinados. A análise de conteúdo, como técnica de abordagem documental e de análise da comunicação, contribuiu na investigação e organização dos dados, derivadas da delimitação das categorias de referência (fronteiras, direitos humanos, direitos, proteção social, assistência social). Em relação à análise de conteúdo, entende-se que é um processo pelo qual se pode compreender a realidade através da interpretação de textos ou discursos que tenham vínculo com o real. Como técnica de abordagem documental e de análise da comunicação expressa nos documentos, visa-se encontrar "[...] por meio de procedimentos sistemáticos e objetivos de descrição do conteúdo das mensagens, indicadores (quantitativos ou não) que permitam a inferência de conhecimentos relativos às condições de produção/recepção dessas mensagens" (BARDIN, 1979, p. 42).

O texto apresenta, inicialmente, um debate atual sobre a temática da fronteira e suas particularidades enquanto espaços complexos, contendo elementos de contradição, integração e conflito que reverberam nas políticas públicas locais e regionais. Na segunda parte, são apresentados os principais dispositivos jurídico-administrativos que tratam da dimensão social e relações fronteiriças, emanadas do Mercosul. Mesmo os documentos que não dizem respeito diretamente à proteção social e relações transfronteiriças têm, indiretamente, relação com esse espaço, podendo contribuir na implementação de políticas sociais nacionais, bilaterais e regionais. Na terceira parte, importou identificar quantas referências e quais proposituras de ações encontram-se elencadas no Plano de Ação Social do

\footnotetext{
${ }^{1}$ A concepção de institucionalidade aqui adotada é relativa ao respeito às regras institucionais, democraticamente consensuadas, permitindo continuidades regulatórias nos processos de gestão e garantindo a efetividade de suas atribuições na transição entre o plano ético-político e o plano técnico-operativo (AGUSTINI; NOGUEIRA, 2010, p. 4).

2 O termo assistência social foi utilizado com o mesmo sentido de socioassistencial. Optou-se pelo primeiro por ser o utilizado no Brasil.
} 
Mercosul que fazem menção às categorias fronteira, direitos, direitos humanos, proteção social e assistência social com impactos em territórios de fronteira e nas políticas públicas, com ênfase na política da assistência social.

\section{Territórios de fronteiras e suas particularidades}

A linha ou zona de fronteira assinala um "[...] espaço de interação, uma paisagem específica, com espaço social transitivo, composto por diferenças oriundas da presença do limite internacional, e por fluxos e interações transfronteiriças, cuja territorialização mais evoluída é a das cidades gêmeas" (BRASIL, 2005a, p. 21). O primeiro ponto a observar é a assimetria existente entre as fronteiras, visto serem transpassadas por movimentos e processos sociais, históricos, culturais, econômicos, políticos, geográficos e jurídicos. Configuram, assim, lugares heterogêneos, dotados de múltiplas espacialidades e constituídos de histórias, culturas, identidades, correlações de forças políticas e relações de poder. Tais distinções são determinadas geralmente pela forma de apropriação capitalista do território e transformações no mundo do trabalho impostas, em diferentes graus de intensidade (SANTOS, 1996).

A construção do cotidiano da vida em territórios de fronteira se (re)constitui e se (re)define na organização do espaço social, na diversidade de movimentos de todos os matizes, determinantes nas relações de vivências, de pertencimentos e identidades que suplantam as nacionalidades institucionalizadas no âmbito jurídico-formal. Reverberam nos espaços socialmente organizados "[...] por meio de muitas travessias e contornos das leis estatais que inscrevem, no território de moradia, os limites entre o cidadão e o estrangeiro" (ALBUQUERQUE, 2015, p. 98). As fronteiras internacionais,

[...] nos ajudam a compreender as dinâmicas de uma nação porque ali a realidade nacional é contrastada, naturalizada ou questionada por sujeitos que se constituem em contato com o(s) outro(s). Olhar para a fronteira é, também, observar tudo aquilo que afirma uma realidade local, regional, transfronteiriça por meio de práticas, relações e narrações que têm a função de consolidar maneiras de ser naquele lugar (PAIVA; ALBUQUERQUE; CARDIN, 2018, p. 18).

Nas cidades fronteiriças conurbadas, ou cidades gêmeas, a percepção de nação, 
nacionalidade e proteção torna-se mais complexa. Não se observa unicamente um entrelaçamento entre os traçados urbanos das duas cidades; há, sobretudo, uma imbricação da história e da vida das pessoas em um espaço que se torna, inúmeras vezes, comum. Diferente dos deslocamentos ou migrações transoceânicos ou transcontinentais, as particularidades dos deslocamentos dos residentes fronteiriços das cidades gêmeas são de curta distância, com o objetivo de ir ao trabalho, estabelecer trocas comerciais, acessar os serviços de saúde, educação, assistência social, entre outros, no país vizinho, sem fixar residência, os quais são compreendidos como movimentos populacionais pendulares. São territórios vinculados a uma identidade nacional que se dilui e onde se manifestam situações de dubiedade, diferença versus integração, nas quais, além de diferença de língua e cultura, há convivência cotidiana entre distintos sistemas políticos, monetários, de segurança e de proteção social (CICCOLELLA, 1994). É o espaço social vivido e continuamente (re)construído, gerador tanto de tensões como de afinidades, integrações regionais e assimetrias socioeconômicas, possibilidades e contradições entre as realidades local, regional e global, entre "os de lá e os de cá" da fronteira. É a síntese concreta e histórica da instância espacial ontológica dos processos sociais, produto e meio de produção e reprodução de toda a vida social (SANTOS, 1979).

Nessa perspectiva, o território fronteiriço é entendido como um espaço denso de relações sociais, potencialidades e necessidades, atravessado por mecanismos de resistência e lutas coletivas, pela ampliação e construção de espaços de democracia, cidadania e participação nas arenas políticas multilaterais. É o território dos espaços vividos e entrelaçados pela diferença e pelo reconhecimento da diversidade que transcende as fronteiras estatais, de tal forma que o entendimento do território fronteiriço pode ser interpretado não só como um espaço geográfico e geopolítico cindido, mas como espaço imbricado de experiências e sentidos que se estabelecem nas interações sociais cotidianas dos residentes fronteiriços, em suas articulações e construções políticas, econômicas, culturais e socioafetivas. Nos territórios de fronteiras:

O chão e suas circunstâncias deixam de ser um dado natural e tornam-se uma construção humana. [...] sobre a topografia da natureza ergue-se uma topografia social, ela incorpora a concretude de condições e acessos como dois elementos imbricados mutuamente e dependentes. Já não se está simplesmente falando de um lugar como vazio, mas do resultado da ocupação e da ação dos sujeitos cidadãos, ou quase cidadãos (KOGA, 2011, p. 16).

As demandas de proteção social dos residentes fronteiriços, a organização, o acesso 
aos bens e serviços públicos, bem como a fruição destes, não se restringem aos limites político-administrativos de um Estado nacional, definidos no âmbito jurídico-formal. Assim, o conhecimento dos dispositivos regionais, constitucionais, infraconstitucionais, jurídicos e programáticos do PEAS pode contribuir para a problematização, concepção e implementação de políticas sociais locais, nacionais e bilaterais, quando dialogam com as necessidades e a realidade local/regional, evidenciadas nos territórios de fronteiras do Mercosul. Neste artigo, privilegiou-se a relação entre o PEAS e a política de assistência social.

\section{Dimensão social do Mercosul e relações fronteiriças}

Em 26 de março de 1991, Argentina, Brasil, Paraguai e Uruguai (Estados Partes) deliberaram pela criação do Mercosul, de caráter intergovernamental, como parte da estratégia de alianças econômicas, geopolíticas e militares da rearticulação mundial do capital. Posteriormente são incorporados, na condição de Estados Associados, os seguintes países: Bolívia (1996), Chile (1996), Peru (2003), Colômbia (2004), Equador (2004), Venezuela 3 (2012), Guiana (2013) e Suriname (2013).

A implementação do Mercosul sofreu diversos reveses desde sua criação. Em sua origem, os objetivos específicos da integração regional restringiam-se ao campo econômicocomercial e aos aspectos aduaneiros, deflagrados no contexto da mundialização do capital e rearranjo internacional da divisão social e técnica do trabalho, a partir da década de 1980 . Os impactos dos ajustes econômicos e as (contra)reformas impostas ao conjunto dos países do Mercosul, "[...] com perdas consideráveis nas formas de proteção social construídas em períodos anteriores e na retração das políticas sociais públicas ${ }^{4}$, tornaram mais crítica a situação de pobreza e desigualdade" (SIMIONATTO; NOGUEIRA, 2006, p. 204). Os países integrantes do bloco reconheceram a exigência dessa situação crítica e, paulatinamente, foram sendo incluídos na agenda temas relacionados à área social. O tema proteção social apareceu pela primeira vez em 1998, com a assinatura da Declaração Sociolaboral do

\footnotetext{
${ }^{3}$ A Venezuela se encontra suspensa de todos os direitos e obrigações à sua condição de Estado Parte do MERCOSUL desde dezembro de 2016.

${ }^{4}$ No campo das políticas sociais na América Latina, há significativa redução de investimentos e financiamentos, sendo reduzidos a mecanismos compensatórios mínimos, "[...] com cortes em programas destinados aos segmentos de classe mais subalternizados e com menor poder de pressão, o que impede a expansão dos serviços e produz a sua saturação pelo excesso de demanda" (SIMIONATTO; NOGUEIRA, 2006, p. 205).
} 
Mercosul ${ }^{5}$, ao estabelecer um conjunto de princípios e direitos para o desenvolvimento de medidas de proteção social e para o trabalho decente dos trabalhadores e trabalhadoras do bloco regional. Na referida declaração, os Estados Partes comprometem-se a adotar ações e procedimentos comuns, concernentes à circulação dos trabalhadores nas zonas de fronteira, com igualdade de direitos e condições de trabalho, assistência e proteção social de forma compatível com o processo de integração regional (COSTA, 2009; MERCOSUL, 1998). Entretanto, o que se coloca de forma evidente a respeito da proteção social na referida declaração

[...] é a transposição de um modelo de proteção dado pela condição de trabalho e não pela ampliação de um conceito de cidadania, pois o trabalhador do Mercosul é definido como aquele que tem vínculo de emprego com empresas. [...] Assim, é pelo estatuto do trabalho, e não pela prevalência dos direitos humanos, que se está construindo a proteção ao trabalhador do Mercosul. [...] Não é por ser cidadão do Mercosul que se tem acesso aos direitos sociais do trabalho, mas pelo vínculo de emprego (COSTA, 2009, p. 77-78).

A partir dos anos 2000, ao se reconhecer a ampliação da dimensão social dos países que integram o Mercosul, foi estabelecida uma agenda social, compreendida como um "[...] conjunto de ações, programas e instituições que se constituem no âmbito da integração regional com o objetivo de redução das assimetrias e das desigualdades sociais nos países do bloco" (OLIVEIRA, 2017, p. 96). A dimensão social ${ }^{6}$ ganha visibilidade a partir da Reunião de Ministros e Autoridades do Desenvolvimento Social (RMADS) do Mercosul e Estados Associados, criada pela Decisão MERCOSUL/CMC/DEC no 61/00. O Conselho do Mercado Comum (CMC) outorgou à RMADS a função de orientar a coordenação de políticas públicas de desenvolvimento e ações conjuntas voltadas ao desenvolvimento nas dimensões social, política, participativa e distributiva dos Estados Partes, com o estabelecimento da "[...] base conceitual comum para os países da região na integração, na formulação, desenho, implementação e na avaliação das políticas sociais regionais" (OLIVEIRA, 2017, p. 97).

Em junho de 2003, durante a XXIV Reunião do Conselho do Mercado Comum, realizada em Assunção, Paraguai, reiterou-se a decisão pela implementação da dimensão social no contexto da integração e desenvolvimento de seus Estados Partes, "[...] enfatizando

\footnotetext{
${ }^{5}$ Esta declaração foi revisada em 2015 (MERCOSUL, 2015).

6 "A dimensão social não foi simplesmente considerada como um complemento da liberdade de circulação, inicialmente destinada apenas aos trabalhadores, mas como uma proteção da pessoa enquanto tal, ou seja, ligada a uma noção mais ampla de direitos fundamentais" (MOURA, 2018, p. 142).
} 
aquelas medidas tendentes a propiciar a inclusão social e econômica dos grupos mais vulneráveis da população" (MERCOSUL, 2010, p. 17). Posteriormente, na Declaração de Buenos Aires, de 14 de julho de 2006, o bloco deliberou por assumir a dimensão social da integração,

[...] baseada em um desenvolvimento econômico de distribuição equitativa, que tende a garantir o desenvolvimento humano integral, que reconhece ao indivíduo como cidadão sujeito de direitos civis, políticos, sociais, culturais e econômicos. Desta forma, a Dimensão Social da integração regional se configura como um espaço inclusivo que fortalece os direitos cidadãos e a democracia (MERCOSUL, 2010, p. 3031).

Com a construção da Agenda Social do Mercosul, foi necessário construir um sistema institucional de garantia de direitos "[...] que opere no espaço supranacional e as possibilidades de superação do conceito clássico de cidadania, como vínculo jurídico centrado na nacionalidade" (COSTA, 2009, p. 66). Dentre as iniciativas nessa linha, levadas à frente pelo Mercosul, destacam-se a criação de dois institutos no âmbito de sua dimensão social: o Instituto Social do Mercosul e o Instituto de Políticas Públicas em Direitos Humanos (IPPDH). Criado em 2007, com sede em Assunção, Paraguai, o ISM é uma instância técnica de pesquisa no campo das políticas sociais e na implementação de linhas estratégicas que objetivam a consolidação da dimensão social como um eixo central no processo de integração, por meio de iniciativas que contribuam para a redução das assimetrias sociais entre os Estados membros (ISM, 2019). Já o IPPDH, criado em 2009, com sede em Buenos Aires -Argentina, tem a missão de fortalecer os direitos humanos como um eixo fundamental da identidade e integração regional, mediante à cooperação e coordenação de políticas públicas (IPPDH, 2019).

Como projetos relevantes para as áreas da proteção social e dos direitos humanos, foram elaborados, em 2010, o Plano Estratégico de Ação Social (PEAS) - Decisão CMC no 67/10 - e o Plano de Ação para Conformação do Estatuto da Cidadania - Decisão CMC no 64/10. 0 PEAS é composto por 10 eixos fundamentais, subdivididos em 26 diretrizes e 101 objetivos prioritários, e estabelece um amplo leque de prioridades para articular as iniciativas que, desde a década de 2000, conformam à dimensão social do processo de integração regional do Mercosul: 
I) Erradicar a fome, a pobreza e combater as desigualdades sociais; II) Garantir os direitos humanos, a assistência humanitária e a igualdade étnica, racial e de gênero; III) Universalizar a Saúde Pública; IV) Universalizar a educação e erradicar o analfabetismo; V) Valorizar e promover a diversidade cultural; VI) Garantir a inclusão produtiva; VII) Assegurar o acesso ao trabalho decente e aos direitos previdenciários; VIII) Promover a Sustentabilidade Ambiental; IX) Assegurar o Diálogo Social; X) Estabelecer mecanismos de cooperação regional para a implementação e financiamento de políticas sociais (MERCOSUL, 2010).

O Plano de Ação para a Conformação do Estatuto da Cidadania estabeleceu três objetivos gerais, que buscam garantir a livre circulação de pessoas no Mercosul, a igualdade de direitos e liberdades civis, sociais, culturais e econômicas para os nacionais dos Estados Partes e a igualdade de condições para o acesso ao trabalho, à saúde e à educação. Entre as ações realizadas, podem ser mencionadas: a) a criação do sistema integrado de mobilidade do Mercosul, que unifica e amplia os programas para concessão de bolsas de intercâmbio para estudantes, professores e pesquisadores de instituições de ensino superior da região; b) a regulamentação dos controles integrados nas fronteiras dos Estados Partes; c) a facilitação dos fluxos migratórios entre os países; e d) a facilitação da circulação de trabalhadores no Mercosul.

Em 2010, a Comissão de Representantes Permanentes do Mercosul (CRPM) editou a chamada Cartilha da Cidadania do Mercosul", na qual estão compiladas as principais normativas de interesse dos países do bloco - incluindo as Declarações Presidenciais dos Estados Partes, decisões CMC, resoluções GMC e recomendações $\mathrm{CMC}$-, que estabelecem as diretrizes políticas que orientam o Mercosul e os Estados Partes. Nela constam 59 iniciativas, divididas em 12 categorias, tais como:

I) circulação de pessoas e bens; II) trabalho e seguridade social; III) educação; IV) defesa do consumidor; V) apoio à produção e ao comércio; VI) correspondências e encomendas; VII) cooperação consular e jurídica; VIII) direitos humanos; IX) integração cultural; X) aspectos sanitários e de saúde; XI) dimensão social; e XII) temas diversos. Esta cartilha tem sido objeto de constante atualização normativa em sua versão digital (MERCOSUL, 2016).

Quanto aos impactos das 59 iniciativas nas fronteiras, Desiderá Neto e Penha (2016)

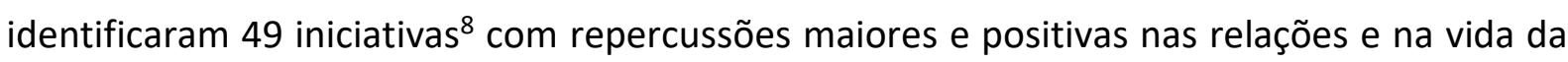

\footnotetext{
${ }^{7}$ A Cartilha da Cidadania do Mercosul lista iniciativas relacionadas com os seguintes tipos de normativas: declarações presidenciais, decisões CMC, resoluções GMC e recomendações CMC. Para este estudo, não foram incluídas as recomendações, por elas não apresentarem nenhum caráter vinculante.

${ }^{8}$ Dentre as 49 inciativas elencadas por Desiderá Neto e Penha (2016) com impactos positivas nos territórios de fronteira, destacam-se, neste trabalho: "Residência para nacionais dos Estados partes do Mercosul, Bolívia,
} 
população fronteiriça, se comparadas com os territórios dos Estados nacionais não situados em regiões de fronteiras. Essa aferição, segundo os autores (DESIDERÁ NETO; PENHA, 2016, p. 210), “[...] corrobora o argumento de que esses territórios são laboratórios da integração, nos quais demandas são formadas e soluções são experimentadas" localmente, contribuindo para a convivência transfronteiriça e para o desenvolvimento de políticas públicas integradas, com perspectivas de resolutividade para as problemáticas e vulnerabilidades socioeconômicas da fronteira, possuidoras de especificidades e peculiaridades muitas vezes ignoradas.

Os acordos sobre a migração e a residência dos cidadãos dos Estados Partes do Mercosul (Decisão CMC no 28/02; Decisão CMC no 04/11; Decisão CMC no 21/11; Decisão CMC no 20/12) permitem a circulação, residência e simplificações e se referem ao processo normativo para a regularização migratória de cidadãos do Mercosul, Colômbia, Bolívia, Chile, Equador e Peru. Tais acordos "[...] são relevantes na medida em que se compreende que o direito à residência, resultado direito da circulação do indivíduo, pode ser considerado um primeiro grau de pertença, e a cidadania, o passo subsequente" (MOURA, 2018, p. 141).

Destaca-se, ainda, a criação do Grupo Ad Hoc sobre Integração Fronteiriça (GAHIF), em 2002, com o objetivo de elaborar instrumentos normativos para promover a integração das comunidades fronteiriças, "[...] tendo em vista a melhoria da qualidade de vida dessas populações e sem prejuízo para os regimes nacionais ou os negociados entre dois ou três Estados partes" (DESIDERÁ NETO; PENHA, 2016, p. 34). Ainda sob o ponto de vista das fronteiras, no ano de 2004 foram criados, no âmbito do Mercosul, o Fórum Consultivo de Municípios, Estados Federados, Províncias e Departamentos do Mercosul (FCCR) e o Fundo para a Convergência Estrutural do Mercosul (FOCEM). Em 2007, o FCCR deliberou pela criação do Grupo de Trabalho sobre Integração Fronteiriça (GTIF), "[...] incorporando para si a função de estabelecer um fluxo formal de colocação de demandas das entidades subnacionais de

Chile, Colômbia, Equador e Peru; Dispensa de tradução de documentos administrativos para efeitos de imigração entre os Estados partes do Mercosul; Acordo multilateral de seguridade social do Mercosul; Condições mínimas do procedimento de inspeção do trabalho no Mercosul; Protocolo de integração educativa e revalidação de diplomas, certificados, títulos e reconhecimento de estudos de nível médio técnico; Protocolo de integração educacional para prosseguimento de estudos de pós-graduação nas universidades dos Estados partes do Mercosul; Promoção e proteção dos direitos humanos no Mercosul; Instituto de Políticas Públicas de Direitos Humanos; Acordo contra o tráfico ilícito de migrantes entre os Estados partes do Mercosul; Mecanismo de articulação para a atenção às mulheres em situação de tráfico internacional; Integração cultural do Mercosul; Informação básica comum para a caderneta de saúde da criança; Estatuto da Cidadania - Plano de Ação; PEAS; Instituto Social do Mercosul (ISM); Unidade de Apoio à Participação Social (UAPS)" (DESIDERÁ NETO; PENHA, 2016, p. 211-213). 
fronteiras perante os governos centrais" (DESIDERÁ NETO; PENHA, 2016, p. 35). O FOCEM estabeleceu um fundo para o financiamento de projetos que promovam a redução das assimetrias entre os países do Mercosul, com o objetivo principal de melhorar a conectividade da infraestrutura de transportes e contribuir para elevar a qualidade de vida da população dessas regiões, combatendo a pobreza e o desemprego (DESIDERÁ NETO; PENHA, 2016). Também é significativo o Acordo sobre Localidades Fronteiriças Vinculadas, assinado entre países limítrofes do Mercosul. Aplica-se aos nacionais domiciliados dentro dos limites territoriais, previstos no Anexo do Acordo. Dentre os direitos concedidos aos residentes fronteiriços, encontram-se a expedição da carteira de trânsito vicinal fronteiriço; o livre exercício de trabalho ou profissão, gozando de iguais direitos e obrigações trabalhistas e previdenciárias; o acesso ao ensino público e o atendimento médico nos serviços públicos de saúde em condições de gratuidade e reciprocidade.

Considerando os principais dispositivos jurídico-administrativos para a implementação das proposituras da dimensão social do Mercosul - entre eles o direito humano à proteção social -, existe ainda um complexo caminho a percorrer e enfrentar.

\section{A institucionalidade do direito humano à proteção social no Plano Estratégico de Ação Social do Mercosul}

Os sistemas de proteção social, fundamentados nos direitos humanos, têm como norma universal a dignidade do ser humano, a ser garantida pelo Estado, através das políticas públicas, especialmente de corte social. O sistema de proteção social caracteriza-se por um conjunto de políticas e programas governamentais "[...] destinados à prestação de bens e serviços e à transferência de renda, com o objetivo de cobertura dos riscos sociais, garantia dos direitos sociais, equalização de oportunidades e enfrentamento das condições de destituição e pobreza" (CARDOSO JUNIOR; JACCOUD, 2005, p. 194). O Estado e as políticas sociais,

[...] devem se estruturar para a efetivação desses direitos, resultantes de pactos políticos, de leis e de normas, segundo a correlação de forças da sociedade organizadas na superestrutura jurídico-política no Estado de direito, configurando a cidadania protegida. O cidadão ou cidadã devem ter assegurados, pelo Estado e pela sociedade, as condições de vida digna na sua história e na sua trajetória, tornandose credores do Estado de direitos para viver e conviver com liberdade, igualdade, justiça e equidade, democraticamente estabelecidas (FALEIROS, 2013, p. 85-86). 
O direito humano à proteção social está vinculado à ideia de uma cidadania ativa, na garantia da autonomia em situações cotidianas e reais. Recusa-se, portanto, um ideal de direito social que não se identifique no plano concreto, garantindo a universalidade e integralidade da proteção social. Na efetivação do direito de proteção social, são necessárias condições objetivas, entre estas a existência de uma arena política na qual a convergência ou divergência dos interesses dos sujeitos define o nível de proteção social através de políticas públicas.

A institucionalidade das políticas públicas produz, contraditoriamente, relações e posições de poder que revelam, ao mesmo tempo e no mesmo processo, o aprofundamento de práticas restritivas capazes de romper ou produzir barreiras para as possibilidades de ação na garantia dos direitos, como a criação de estratégias comprometidas com a liberdade e formas de operar a universalização do acesso e fruição de direitos da população, nos seus territórios de abrangência. As estratégias e instrumentos de gestão adotados para a institucionalização e operacionalização da política pública podem se configurar com distintos conteúdos políticos e abrem a possibilidade de abordar o Estado em ação, interferindo, por meio de seus agentes, em uma dada realidade social com determinada dimensão éticopolítica, especialmente em territórios de fronteira internacional. Na América Latina, esses territórios são marcados por altas taxas de desigualdade, que se somam às desigualdades nacionais persistentes nessa região do continente americano, onde carências de recursos de infraestrutura e dificuldades de acesso aos bens e serviços de proteção social compõem a cidadania social.

A assistência social, política pública de direito social no campo dos direitos humanos, assim como as outras políticas sociais de proteção social, se expressa territorialmente e "[...] contribui também para lógicas de organização do espaço nas cidades e no campo, territorializando os espaços, isto é, dotando-os de sentidos" (PEREIRA, 2009, p. 14). O território é o "[...] terreno das políticas públicas, onde se concretizam as manifestações da questão social e se criam os tensionamentos e as possibilidades para seu enfrentamento" (COUTO; YAZBEK; RAICHELIS, 2010, p. 50).

Nos países do Mercosul, existem diferenças relacionadas à concepção, institucionalização e operacionalização da proteção social no âmbito da assistência social, que sinalizam diferenciadas ações e impactos nos territórios de fronteiras internacionais, como é 
o caso de Argentina ${ }^{9}$, Brasil $^{10}$, Paraguai $^{11}$ e Uruguai ${ }^{12}$.

No Brasil, a Lei Orgânica da Assistência Social (LOAS), instituída em 2003, aliada à implantação da Política Nacional de Assistência Social em 2004, impõe um novo ordenamento ao setor, devendo as ações serem desenvolvidas através de um sistema descentralizado e participativo, denominado Sistema Único de Assistência Social (SUAS). Como sistema público, o SUAS está no âmbito da Seguridade Social e deve garantir proteção social:

A proteção social de Assistência Social se ocupa das vitimizações, fragilidades, contingências, vulnerabilidades e riscos que o cidadão, a cidadã e suas famílias enfrentam na trajetória de seu ciclo de vida, por decorrência de imposições sociais, econômicas, políticas e de ofensas à dignidade humana. A proteção social de Assistência Social, em suas ações, produz aquisições materiais, sociais, socioeducativas ao cidadão e cidadã e suas famílias para: suprir suas necessidades de reprodução social de vida individual e familiar; desenvolver suas capacidades e talentos para a convivência social, protagonismo e autonomia (BRASIL, 2005b, p. 89).

Para identificar a institucionalidade e a pactuação do direito humano à proteção social no Mercosul, utilizaram-se como parâmetro as definições contidas no SUAS, correlacionando-as com o Plano Estratégico de Ação Social (PEAS). Importou conhecer quantas referências e quais proposituras de intervenção encontram-se elencadas no documento supracitado, que faz menção às categorias fronteiras, direitos e direitos humanos e proteção social, com imediatos desdobramentos em territórios de fronteira e nas políticas públicas, dentre elas, a Assistência Social.

9 Na Argentina, sob a responsabilidade do Ministerio de Desarrollo Social, os serviços de proteção social de assistência social se concentram em três grandes linhas: economia social, políticas alimentares e famílias de maior vulnerabilidade, ainda que vários serviços e direitos estejam distribuídos entre outros ministérios.

${ }^{10}$ No Brasil, a assistência social é política de Seguridade Social, junto com a Saúde e Previdência Social. Com a instituição do Sistema Único de Assistência Social (SUAS), sob responsabilidade do Ministério do Desenvolvimento Social, a proteção social está organizada em: I) Proteção Social Básica, que busca prevenir riscos sociais e pessoais de indivíduos e famílias em situação social vulnerável; II) Proteção Social Especial (subdividida de média e alta complexidade),que objetiva atender as famílias ou indivíduos com seus direitos violados por ocorrência de abandono, maus-tratos físicos ou psíquicos, abuso sexual, cumprimento de medidas socioeducativas, situação de rua, situação de trabalho infantil.

${ }^{11}$ No Paraguai, a assistência social consiste na provisão focalizada de serviços e renda para pessoas em situação vulnerável, sobretudo indígenas, sob responsabilidade da Secretaria de Acción Social e da Dirección de Pensiones no Contributivas do Ministério da Fazenda. São dois os principais programas de proteção social no Paraguai: I) os programas de transferência de renda para combater a pobreza no curto e médio prazo; e II) as pensões não contributivas para a população idosa de 65 anos ou mais.

12 No Uruguai, o Ministério del Desarrollo Social é responsável pela coordenação da assistência social. Os principais programas de proteção social são a Tarjeta Uruguay Social, que tem como objetivo favorecer o acesso aos bens básicos; o Programa de Asignación Familiar, com transferência monetária condicional focada nas famílias de baixa renda; e as políticas de proteção de crianças e adolescentes e de acesso aos alimentos saudáveis. 
A categoria fronteira não foi mencionada nos eixos prioritários do PEAS. Entre as 26 diretrizes, há uma indicação que trata do fomento à integração produtiva, com vistas a beneficiar áreas de menor desenvolvimento e segmentos vulneráveis da população fronteiriça. Quanto aos objetivos prioritários do PEAS, 10 fazem menção e têm relação direta com a fronteira, com destaque as seguintes ações: Articular e implementar políticas públicas de caráter socioeducativo para adolescentes que cometeram ato infracional, especialmente nas regiões de fronteira; Promover acordos regionais que garantam acesso à saúde pública na faixa de fronteira; Fortalecer a integração regional a partir de estratégias e ações concretas com as instituições educativas, incluindo os municípios participantes do Programa Escolas de Fronteira; Fomentar o potencial cultural das zonas fronteiriças através da elaboração de políticas conjuntas; Estimular o acesso de setores vulneráveis da população às atividades produtivas globais e integradas, além de estimular o investimento em infraestrutura; Garantir às trabalhadoras domésticas os direitos trabalhistas, especialmente nas regiões de fronteira; Criar unidades produtivas em setores estratégicos e intensivos em mão de obra, prioritariamente na região de fronteira, especialmente para jovens e outros grupos em situação social desfavorecida; Promover medidas para a regularização dos trabalhadores informais, especialmente nas áreas de fronteira (MERCOSUL, 2010).

Em relação à categoria direitos e direitos humanos, entre os 10 eixos fundamentais do PEAS, 2 deles destacam a garantia dos direitos humanos, a assistência humanitária e a igualdade étnica, racial e de gênero, e o acesso ao trabalho decente e aos direitos previdenciários. Das 26 diretrizes do PEAS, 4 expressam a necessidade de assegurar os direitos civis, culturais, econômicos, políticos e sociais, sem discriminação por motivo de gênero, idade, raça, etnia, orientação sexual, religião, opinião, origem nacional ou social, condição econômica, a pessoas com deficiência ou qualquer outra condição; bem como a livre circulação no Mercosul, acompanhada do pleno gozo dos direitos humanos, o acesso aos serviços públicos como um direito básico e a execução de políticas educativas que promovam o respeito aos direitos humanos.

Dos 101 objetivos prioritários do PEAS, 10 destacam a posição do Mercosul em relação aos direitos, tais como o fortalecimento do Instituto de Políticas Públicas de Direitos Humanos do Mercosul; a coordenação e posições em temas de direitos humanos em organismos internacionais; a promoção e defesa de direitos dos grupos LGBT, idosos, 
migrantes e refugiados; das mulheres no acesso à terra, à reforma agrária e ao desenvolvimento rural sustentável e garantia dos direitos trabalhistas às trabalhadoras domésticas; o direito à educação sexual e reprodutiva nas escolas; e a criação de um sistema de indicadores sobre a situação dos direitos humanos no Mercosul.

Quanto à proteção social, com ênfase na Política de Assistência Social (proteção socioassistencial), foram identificadas referências de ações em 3 eixos fundamentais, 4 diretrizes e 21 objetivos prioritários do PEAS. Os eixos fundamentais identificados abordam a erradicação da fome, a pobreza e o combate às desigualdades sociais; a garantia dos direitos humanos; a assistência humanitária e a igualdade étnica, racial e de gênero; e a cooperação regional para a implementação e financiamento de políticas sociais. As diretrizes que se articulam com a proteção socioassistencial sinalizam para a promoção de políticas distributivas na perspectiva de gênero, idade, raça e etnia; o fortalecimento da assistência humanitária; a valorização e difusão da diversidade cultural dos países do Mercosul; e o impulso ao diálogo entre as organizações sociais e órgãos responsáveis pela formulação e gestão de políticas sociais.

Os objetivos prioritários do PEAS apontam ações interventivas que se vinculam aos processos interventivos no campo da proteção socioassistencial. As referências e demandas identificadas, por consequência, a serem operadas na assistência social através da oferta serviços e de programas que visem o enfrentamento da desproteção social, estão relacionadas à garantia e acesso aos serviços dessa política social pelas famílias e pessoas em situação de vulnerabilidade e risco social; programas de transferência renda; o fortalecimento, nas linhas de fronteira, das redes de proteção e promoção social; a proteção integral à criança e ao adolescente em situação de violência e exploração sexual e contra o uso de drogas e trabalho infantil (prevenção e erradicação); incremento de políticas socioeducativas para adolescentes autores de ato infracional; políticas públicas voltadas para atenção à população em situação de rua; o combate de todas as formas de violência, discriminação e preconceito; o monitoramento da situação dos direitos humanos no Mercosul; a incorporação nas políticas sociais de ações de prevenção, proteção e atenção para erradicação de todas as formas de violência, especialmente contra as mulheres e as meninas, de respeito aos direitos humanos, integração e proteção dos migrantes e refugiados, e às populações atingidas por situações emergenciais. Cabe destaque para a criação e fortalecimento de fundos específicos para políticas e projetos regionais. 
As indicações acima permitem apreciar o conjunto de propostas factíveis de ampliação da cidadania social a partir dos dispositivos institucionais já existentes. Permitem, ainda, estabelecer algumas inferências possíveis para alcançar o desiderato proposto nos documentos, as quais são sintetizadas nas considerações finais deste artigo.

\section{Considerações Finais}

Retomando o objetivo previsto para o artigo: estabelecer a interface entre o PEAS e a política de assistência social, salienta-se a importância de se estudar as decisões, acordos e recomendações emanados no âmbito do Mercosul, os quais são indicativos fundamentais para se discutir a estruturação da cidadania social dos Estados Partes. Lembrando, igualmente, que as possibilidades para a institucionalização e operacionalização de serviços de proteção socioassistencial aos residentes fronteiriços estão relacionadas à necessária articulação institucional transfronteiriça para o atendimento conjunto em casos de desproteção social e violação de direitos humanos; à realização de atividades factíveis que conduzam a uma cooperação transfronteiriça com participação da população local; à apropriação e aproximação entre o proposto nos acordos e normativas do Mercosul e sua efetivação em nível local e regional, acompanhada de debates que favoreçam sua apropriação pelos atores locais e pela própria população da faixa de fronteira; e à manutenção e ampliação das ações exitosas pactuadas entre os atores políticos (gestores e executores da política social) das cidades gêmeas fronteiriças, que contribuem para evitar a redução ou anulação de serviços de proteção socioassistencial transfronteiriços em andamento.

Destaca-se, no PEAS, a indicação do fortalecimento das fronteiras; da promoção de intercâmbio de iniciativas e experiências exitosas; da necessidade de assegurar os direitos civis, culturais, econômicos e políticos.

Outro ponto a se destacar é a relevância dos acordos, quando internalizados na ordem jurídica dos países e acompanhados de normativas nacionais que os materializem. Ou seja, o potencial normativo dos acordos e normas pode alterar padrões de comportamento não inclusivos e excludentes, pois, conforme indicação do Plano Estratégico de Ação Social (PEAS) e do Plano de Ação para Conformação do Estatuto da Cidadania, o desenvolvimento das regiões de fronteira pode diminuir as desigualdades sociais nos níveis nacional e internacional. 
Assim, a análise do documento expressa a institucionalidade desejada pelo Mercosul, através do ISM, ao formular sua concepção de integração transfronteiriça na perspectiva dos direitos humanos, compatível com as formulações contidas na política de assistência social.

Entretanto, dado o caráter não vinculante dos países quanto às normativas do Mercosul na área social, não há garantias de concretização do disposto no documento. 0 alcance do plano demandará outras estratégias, entre elas o debate frequente sobre as ações desenvolvidas. Entende-se ser fundamental a manutenção e a ampliação de encontros/seminários para debater, pactuar e implementar ações bilaterais inerentes à oferta e garantia de acesso aos serviços de proteção socioassistencial dos residentes fronteiriços, referenciados no Plano Estratégico de Ação Social do Mercosul, envolvendo gestores, profissionais, policy makers e população.

Em que pesem as estratégias sugeridas entende-se ser fundamental "[...] reconhecer que proteção social, institucionalidades e Mercosul estão ligados a três temas interrelacionados [...], a saber: integração regional, direitos e cidadania" (NOGUEIRA, 2008).

\section{Referências}

AGUSTINI, Josiane; NOGUEIRA, Vera Maria Ribeiro. A descentralização da política nacional de saúde nos sistemas municipais na linha da fronteira Mercosul. Serviço Social \& Sociedade, São Paulo, n. 102, p. 222-243, abr./jun. 2010. Disponível em: https://www.scielo.br/pdf/sssoc/n102/a03n102.pdf. Acesso em: 14 set. 2018.

ALBUQUERQUE, José Lindomar. Migração, circulação e cidadania em território fronteiriço: os brasiguaios na fronteira entre o Paraguai e o Brasil. TOMO, São Cristóvão, n. 26, p. 97-122, jan./jun. 2015. Disponível em: https://seer.ufs.br/index.php/tomo/article/view/4404. Acesso em: 17 mar. 2019.

BARDIN, Laurence. Análise de conteúdo. Lisboa: Edições 70, 1979.

BRASIL. Ministério da Integração Regional. Proposta de reestruturação do programa de desenvolvimento da faixa de fronteira: bases para uma política integrada de desenvolvimento regional para a faixa de fronteira. Brasília: Ministério da Integração Regional, 2005a.

BRASIL. Ministério do Desenvolvimento Social e Combate à Fome. Secretaria Nacional de Assistência Social. Política Nacional de Assistência Social PNAS/2004. Brasília: MDS, 2005b. Disponível em:

http://www.mds.gov.br/webarquivos/publicacao/assistencia_social/Normativas/PNAS2004. pdf. Acesso em: 14 nov. 2019.

CARDOSO JUNIOR, José Celso; JACCOUD, Luciana. Políticas sociais no Brasil: organização, 
abrangência e tensões da ação estatal. In: JACCOUD, Luciana (org.). Questão social e políticas sociais no Brasil contemporâneo. Brasília: IPEA, 2005. p. 181-260.

CICCOLELLA, Pablo José. O capitalismo histérico: entre o protecionismo e a integração em blocos econômicos. In: LAVINAS, Lena; CARLEIAL, Liana Maria da Frota; NABUCO, Maria Regina (org.). Integração, região e regionalismo. Rio de Janeiro: Bertrand Brasil, 1994. p. 4353.

COSTA, Lúcia Cortes da. A agenda social do MERCOSUL: a relação Estado nacional e integração regional. Revista Em Pauta, Rio de Janeiro, v. 6, n. 24, p. 65-82, dez. 2009. Disponível em: https://www.epublicacoes.uerj.br/index.php/revistaempauta/article/view/520/579. Acesso em: 14 nov. 2018.

COUTO, Berenice Rojas; YAZBEK, Maria Carmelita; RAICHELIS, Raquel. A política nacional de assistência social e o SUAS: apresentando e problematizando fundamentos e conceitos. In: COUTO, Berenice Rojas; YAZBEK, Maria Carmelita; SILVA, Maria Ozanira da Silva e; RAICHELIS, Raquel (org.). O Sistema Único de Assistência Social no Brasil: uma realidade em movimento. São Paulo: Cortez, 2010. p. 32-65.

DESIDERÁ NETO, Walter Antonio; PENHA, Bruna. As regiões de fronteira como laboratório da integração regional no Mercosul. Boletim de Economia e Política Internacional, Brasília, n. 22, p. 33-50, jan./abr. 2016. Disponível em: http://repositorio.ipea.gov.br/bitstream/11058/6733/1/BEPI_n22_Regi\%C3\%B5es.pdf. Acesso em: 11 ago. 2018.

FALEIROS, Vicente de Paula. Desafios de atendimento no Serviço Social: uma perspectiva crítica. Revista Katálysis, Florianópolis, v. 16, n. esp., p. 83-91, 2013. Disponível em: https://www.scielo.br/pdf/rk/v16nspe/06.pdf. Acesso em: 2 nov. 2019.

INSTITUTO DE POLÍTICAS PÚBLICAS EM DIREITOS HUMANOS. Missão, visão e objetivos. Buenos Aires, 2019. Disponível em: http://www.ippdh.mercosur.int/pt-br/missao-visao-eobjetivos/. Acesso em: 12 fev. 2019.

INSTITUTO SOCIAL DEL MERCOSUL. Sobre o ISM. 2019. Disponível em http://www.ismercosur.org/institucional/?lang=pt-br. Acesso em 24 fev. 2019

KOGA, Dirce. Medidas de cidades: entre territórios de vida e territórios vividos. São Paulo: Cortez, 2011.

MERCOSUl. Cartilha da Cidadania do Mercosul: compilação de normas relacionadas com o cidadão e a cidadã do Mercosul. Montevidéu, 2016. Disponível em: http://www.cartillaciudadania.mercosur.int/pt. Acesso em: 11 dez. 2018.

MERCOSUL. Declaração sociolaboral do Mercosul de 2015. Brasília, 2015. Disponível em: http://www.itamaraty.gov.br/pt-BR/notas-a-imprensa/10519-declaracao-sociolaboral-domercosul-de-2015-i-reuniao-negociadora-brasilia-17-de-julho-de-2015. Acesso em: 18 out. 2018. 
MERCOSUL. Declaração sociolaboral do Mercosul. Rio de Janeiro, 1998. Disponível em: http://www.dhnet.org.br/direitos/deconu/a_pdf/dec_sociolaboral_mercosul.pdf. Acesso em: 18 out. 2018.

MERCOSUL. Plano Estratégico de Ação Social do Mercosul. Asunción, 2010. Disponível em: http://www.mercosur.int/innovaportal/v/6582/9/innova.front/plano-estrategico-deac\%C3\%A3o-social-peas. Acesso em: 13 jun. 2018.

MOURA, Aline Beltrame de. O Estatuto da Cidadania do Mercosul: é possível uma cidadania regional? Revista Brasileira de Direito, Passo Fundo, v. 14, n. 2, p. 135-153, maio/ago. 2018. Disponível em:

https://seer.imed.edu.br/index.php/revistadedireito/article/view/1783/1829. Acesso em: 19 mar. 2019.

NOGUEIRA, Vera Maria Ribeiro. Direitos e cidadania nos processos de integração regional: o caso Mercosul. In: BOSCHETTI, Ivanete (org.). Política social no capitalismo: tendências contemporâneas. São Paulo: Cortez, 2008. p. 149-173.

OLIVEIRA, Giseli Aparecida de. Dimensão social do Mercosul: enfoque na realidade paraguaia por meio do Fundo de Convergência Estrutural do Mercosul. Revista MERCOSUR de Políticas Sociales, Asunción, v. 1, p. 96-127, 2017. Disponível em:

http://revista.ismercosur.org/index.php/revista/article/view/17/13. Acesso em: 17 set. 2018.

PAIVA, Luiz Fábio; ALBUQUERQUE, José Lindomar; CARDIN, Eric. A fronteira como campo de pesquisa. Revista de Ciências Sociais, Fortaleza, v. 49, n. 3, p. 15-23, nov./fev. 2018. Disponível em: http://www.periodicos.ufc.br/revcienso/article/view/35668. Acesso em: 12 nov. 2019.

PEREIRA, Tatiana Dahmer. Política Nacional de Assistência Social e Território: um estudo à luz de David Harvey. 2009. Tese (Doutorado em Planejamento Urbano e Regional) Universidade Federal do Rio de Janeiro, Rio de Janeiro, 2009. Disponível em:

http://www.dominiopublico.gov.br/pesquisa/DetalheObraForm.do?select_action=\&co_obra =174200. Acesso em: 19 mar. 2017.

SANTOS, Milton. A natureza do espaço: técnica e tempo, razão e emoção. São Paulo: Hucitec, 1996.

SANTOS, Milton. Por uma geografia nova. São Paulo: HUCITEC, 1979.

SIMIONATTO, Ivete; NOGUEIRA, Vera Maria Ribeiro. As demandas de pesquisas sobre proteção social no Mercosul: exigências para o Serviço Social. Revista Katálysis, Florianópolis, v. 9, n. 2, p. 200-208, jul./dez. 2006. Disponível em: https://www.scielo.br/pdf/rk/v9n2/a07v09n2.pdf. Acesso em: 23 nov. 2018. 